\title{
ANALISIS FAKTOR-FAKTOR YANG MEMPENGARUHI DIVIDEND PAYOUT RATIO PADA PERUSAHAAN MANUFAKTUR YANG TERDAFTAR DI BEI
}

\author{
Raja Saul Marto Hendry \\ Sekolah Tinggi Ilmu Ekonomi Labuhanbatu
}

\begin{abstract}
Penelitian ini bertujuan untuk menguji pengaruh Cash Position, Debt To EquityRatio , Return On Asset, Cash Ratio , Asset Growth, dan Firm Size terhadap Dividend Payout Ratio untuk perusahaan manufaktur yang terdaftar di Bursa Efek Indonesia 20011-2013.

Sampel penelitian terdiri dari 18 perusahaan dan dari laporan keuangan yang telah diaudit. Teknik analisis data dalam penelitian ini menggunakan analisis regresi linier berganda. Pengujian hipotesis dengan menggunakan uji $\mathrm{t}$ untuk menguji pengaruh variabel secara parsial dan uji $\mathrm{F}$ untuk menguji pengaruh variabel secara serentak.
\end{abstract}

Hasil uji t dari persamaan regresi yang didapat menunjukkan bahwa Debt ToEquity Ratio, Return on Asset, dan Cash Ratio secara signifikan mempengaruhi Dividend Payout Ratio, sedangkan Cash Potition, Asset Growth, dan Firm Size tidak berpengaruhterhadap Dividend Payout Ratio.

Hasil uji F menyatakan bahwa semua variabel independen dalam penelitian ini berpengaruh secara signifikan terhadap Dividend Payout Ratio.

Hasil regresi berganda menunjukkan variabel independen mempengaruhi Dividend Payout Ratio sebesar 70,4\%, sedangkan 29,6\% dipengaruhi oleh faktor lain diluar penelitian ini.

Kata kunci: Cash Position, Debt To Equity Ratio, Return on Asset, Cash Ratio , AssetGrowth, dan Firm Size, Dividend Payout Ratio.

\section{PENDAHULUAN}

Kemampuan perusahaan untuk mendapatkan laba yang besar dan usaha mempertahankan investor yang menanamkan saham kepada perusahaan, dalam hubungannya dengan laba yang didapatkan perusahaan yang kemudian di bagi kepada pemegang saham atau ditahan untuk investasi, adalah sangat penting dalam kesinambungan suatu perusahaan.

Perusahaan dalam persaingannya dalam perekonomian nasional maupun global, baik di sektor industri maupun jasa dalam perkembangannya semakin kritis dan tajam, hal ini berakibat terhadap pertumbuhan perusahaan di Indonesia secara kualitas maupun kuantitas menjadi tinggi. Lebih jauh lagi banyaknya perusahaan yang saham-sahamnya yang dahulu hanya dapat dimiliki oleh pemegang saham tertentu saja, yang kemudian menjadi milik publik ketika perusahaannya telah terdaftar di bursa. 
Pada prinsipnya pemenuhan kebutuhan dana suatu perusahaan dapat disediakan dari sumber intern perusahaan, yaitu sumber dana yang dibentuk atau dihasilkan sendiri di dalam perusahaan Riyanto (2008). Penelitian ini akan menguji faktor-faktor yang diduga mempengaruhi kebijakan manajemen mengenai jumlah pembagian dividen. Faktor-faktor yang diduga berpengaruh dan dijadikan variabel bebas dalam penelitian ini adalah Cash Position, Debt To Equity Ratio, Return On Asset, Cash Ratio, AssetGrowth, dan Firm Size. Alasan memilih perusahaan manufaktur sebagai objek penelitianini adalah karena saham perusahaan manufaktur lebih banyak diminati oleh investor dari pada perusahaan bidang lainnya.

Perusahaan manufaktur tidak terikat pada peraturan pemerintah, serta perusahaan manufaktur merupakan salah satu aset yang memiliki peranan penting dalam pembangunan. Sehingga manufaktur mempunyai potensi dalam mengembangkan produknya secara lebih cepat dengan melakukan berbagai inovasi dan cenderung mempunyai ekspansi pasar yang luas dibandingkan perusahan non manufaktur dan jasa. Serta alasan peneliti menambahkan variabel Asset Growth dan Firm zise dalam penelitian ini karena dari penelitian terdahulu memiliki pengaruh signifikan yang berbeda yaitu positif dan negatif mengenai variabel tersebut, sehingga peneliti tertarik untuk melakukan penelitian tersebut.

\section{PERUMUSAN MASALAH}

Berdasarkan latar belakang masalah yang diuraikan diatas, perumusan masalah dalam penelitian ini adalah sebagai berikut:

Apakah Cash Position berpengaruh terhadap Dividend Payout Ratio pada perusahaan manufaktur yang terdaftar di BEI?

Apakah Debt To Equity Ratio berpengaruh terhadap Dividend Payout Ratio pada perusahaan manufaktur yang terdaftar di BEI?

Apakah Return On Asset berpengaruh terhadap Dividend Payout Ratio pada perusahaan manufaktur yang terdaftar di BEI?

Apakah Cash Ratio berpengaruh terhadap Dividend Payout Ratio pada perusahaan manufaktur yang terdaftar di BEI ?

Apakah Asset Growth berpengaruh terhadap Dividend Payout Ratio pada perusahaan manufaktur yang terdaftar di BEI?

Apakah Firm Size berpengaruh terhadap Dividend Payout Ratio pada perusahaan manufaktur yang terdaftar di BEI?

\section{TUJUAN PENELITIAN}

Sesuai dengan masalah yang masalah yang diuraikan diatas, tujuan dilakukannya penelitian ini adalah untuk mengetahui sejauh mana : 
Pengaruh Cash Position terhadap Dividend Payout Ratio pada perusahaan manufaktur yang terdaftar di BEI

Pengaruh Debt To Equity Ratio terhadap Dividend Payout Ratio pada perusahaan manufaktur yang terdaftar di BEI

Pengaruh Return On Asset terhadap Dividend Payout Ratio pada perusahaan manufaktur yang terdaftar di BEI

Pengaruh Cash Ratio terhadap Dividend Payout Ratio pada perusahaan manufaktur yang terdaftar di BEI

Pengaruh Asset Growth terhadap Dividend Payout Ratio pada perusahaan manufaktur yang terdaftar di BEI

Pengaruh Firm Size terhadap Dividend Payout Ratio pada perusahaan manufaktur yang terdaftar di BEI

\section{HIPOTESIS}

Berdasarkan rumusan masalah penelitian maka hipotesisnya adalah sebagai berikut:

Cash Position berpengaruh positif dan signifikan terhadap Dividend Payout Ratio pada perusahaan manufaktur yang terdaftar di BEI

Debt To Equity Ratio berpengaruh positif dan signifikan terhadap Dividend Payout Ratio pada perusahaan manufaktur yang terdaftar di BEI

Return On Asset berpengaruh positif dan signifikan terhadap Dividend Payout Ratio pada perusahaan manufaktur yang terdaftar di BEI

Cash Ratio berpengaruh positif dan signifikan terhadap Dividend Payout Ratio pada perusahaan manufaktur yang terdaftar di BEI

Asset Growth berpengaruh positif dan signifikan terhadap Dividend Payout Ratio pada perusahaan manufaktur yang terdaftar di BEI

Firm Size berpengaruh positif dan signifikan terhadap Dividend Payout Ratio pada perusahaan manufaktur yang terdaftar di BEI

\section{TINJAUAN TEORITIS}

\section{Dividen}

Dividen merupakan nilai pendapatan bersih perusahaan setelah pajak dikurangi dengan laba ditahan (retained eranings) yang ditahan sebagai cadangan perusahaan (Ang, 1997). Menurut Hanafi (2005), 
dividen merupakan kompensasi yang diterima oleh pemegang saham, disamping capital gain. Dividen ditentukan berdasarkan dalam rapat umum anggota pemegang saham dan jenis pembayarannya tergantung kepada kebijakan pemimpin.Kebijakan dividen merupakan bagian yang menyatu dengan keputusan pendanaan perusahaan. Rasio pembayaran dividen menentukan jumlah laba yang ditahan sebagai sumber pendanaan. Semakin besar laba ditahan semakin sedikit jumlah laba yang dialokasikan untuk pembayaran dividen. Kebijakan dividen menyangkut masalah penggunaan laba yang menjadi hak para pemegang saham, dan laba tersebut bisa dibagi sebagai dividen atau laba yang akan diinvestasikan kembali (Husnan, 1996). Dengan demikian dimungkinan membagi laba sebagai dividen dan pada saat yang sama menerbitkan saham baru.Kebijakan dividen bersangkutan dengan penentuan pembagian pendapatan (earning) antara penggunaan pendapatan untuk dibayarkan kepada para pemegang saham sebagai dividen atau untuk digunakan didalam perusahaan, yang berarti laba tersebut harus ditahan dalam perusahaan (Riyanto, 2001) Semakin tinggi tingkat dividen yang dibayarkan, berarti semakin sedikit laba yang ditahan, dan sebagaiakibatnya ialah menghambat tingkat pertumbuhan (rate of growth) dalam pendapatan dan harga sahamnya. Kalau perusahaan ingin menahan sebagian besar dari pendapatan yang tersedia, maka untuk pembayaran dividen adalah semakin kecil. Presentase dari pendapatan yang akan dibayarkan kepada pemegang saham sebagai cash dividen disebut Dividend Payout Ratio. Dengan demikian dapatdikatakan bahwa makin tingginya Dividend Payout Ratio yang ditetapkan oleh perusahaan berarti makin kecil dana yangtersedia untuk ditanamkan kembali di dalam perusahaan yang ini berarti akan menghambat pertumbuhan perusahaan.

\section{Cash Position}

Cash Position dihitung berdasarkan perbandingan antara saldo kas akhir dengan laba bersih setelah pajak (Hanafi, 2005).

\section{Debt To Equity Ratio}

Debt To Equity Ratio merupakan perbandingan jumlah hutang terhadap modal sendiri. Rasio ini mengukur seberapa besar perusahaan dibiayai oleh hutang dibanding dengan modal sendiri (Husnan, 1996).

\section{Return on Assets}

Return On Asset dihitung berdasarkan perbandingan laba bersih setelah pajak terhadap total aktiva yang dimiliki perusahaan (Ang, 1997)

\section{Cash ratio}

Cash Ratio merupakan salah satu ukuran dari rasio likuiditas yang merupakan kemampuan perusahaan memenuhi kewajiban jangka pendeknya melalui sejumlah kas dan setara kas (Riyanto, 2001) 6. Asset Growth

Asset Growth menunjukkan pertumbuhan aset, dimana asset merupakan aktiva yang digunakan untuk aktiva operasional perusahaan (Hanafi, 2005)

\section{Firm Size}


Firm Size sebuah perusahaan diukur dengan menggunakan logaritma natural dari total aset perusahaan yang menjadi sampel didalam penelitian ini. Bentuk logaritma digunakan karena pada umumnya nilai asset perusahaan sangat besar, sehingga untuk menyeragamkan nilai dengan variabel lainnya nilai aset sampel diubah kedalam bentuk logaritma terlebih dahulu (Hanafi, 2005)

\section{METODE PENELITIAN 1.Pengumpulan Data}

Data dalam penelitian ini adalah perusahaan yang sahamnya tergolong dalam sektor manufaktur yang terdaftar di Bursa Efek Indonesia (BEI) untuk periode 2011 - 2013. Adapun kriteria-kriteria yang digunakan dalam penelitian ini mencakup :

\section{Analisis Regresi Berganda Data}

Model analisis yang digunakan untuk menganalisis pengaruh variabel independen terhadap variabel dependen adalah model regresi berganda. Adapun model regresinya sebagai berikut: $\mathrm{Y}=\mathrm{a}+\mathrm{b} 1 \mathrm{X} 1+\mathrm{b} 2$ $\mathrm{X} 2+\mathrm{b} 3 \mathrm{X} 3+\mathrm{b} 4 \mathrm{X} 4+\mathrm{b} 5 \mathrm{X} 5+\mathrm{b} 6 \mathrm{X} 6+\mathrm{e}$ Keterangan

:

Y : Dividend Payout Ratio

a : Konstanta

b1, b2, b3, b4, b5, b6 : Koefisien tiap variabel independen

X1 : Variabel Cash

Position X2 : Variabel

Debt to Equity Ratio

X3 : Variabel Return on

Asset $\mathrm{X} 4$

Variabel Cash Ratio

X5 : Variabel

Asset Growth X6

Variabel Firm

Size e : Error Term

Kriteria pengujian hipotesis secara simultan adalah sebagai berikut :

Nilai F hitung akan dibandingkan dengan F tabel pada tingkat signifikanso $(\alpha)=5 \%$ 
Kriteria penilaian Hipoteris pada uji F ini adalah :

Ho diterima jika : F hitung

$<$ F tabel Ha diterima jika :

F hitung $>\mathrm{F}$ tabel

Kriteria pengujian hipotesis secara parsial adalah sebagai berikut :

Ho diterima jika : $-\mathrm{t}$ tabel $<\mathrm{t}$ hitung $<\mathrm{t}$ tabel

Ha diterima jika ; $\mathrm{t}$ hitung $>\mathrm{t}$ tabel $; \mathrm{t}$ hitung $<-\mathrm{t}$ tabel

\section{HASIL DAN PEMBAHASAN}

\section{A. Regresi Linear Berganda}

\section{Tabel 1}

\section{Pengujian Hipotesi Secara Simultan}

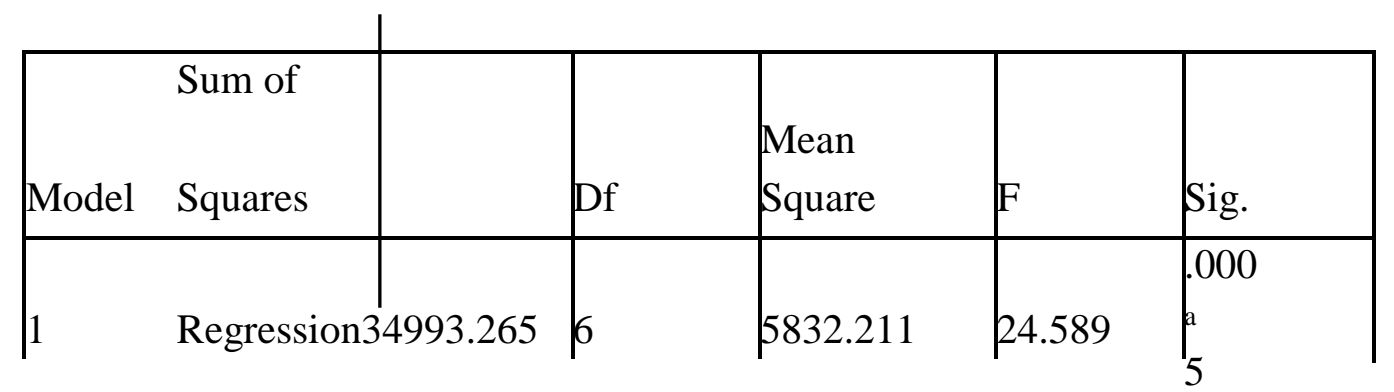


Sumber data : Data primer yang diolah

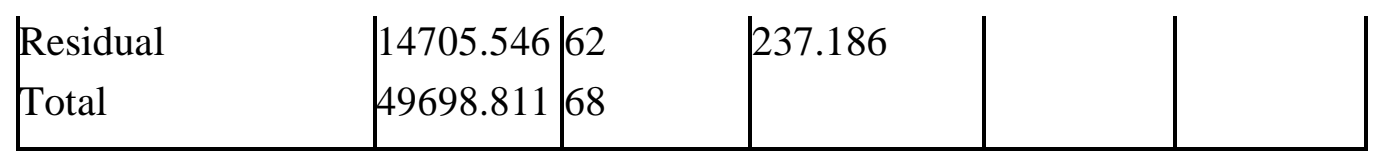

Dari uji ANOVA atau F test diperoleh nilai F hitung sebesar 24,589 dan F tabel 2,70 maka F hitung > F table; maka Ho ditolak dan Ha diterima, dengan demikian Variabel Cash Position,Debt To Equty Ratio,

Return On Asset, Cash Ratio, Asset Growth, dan Firm Size secara simultan berpengaruhsignifikan terhadap Dividen Payout Ratio.

\section{Tabel 2}

\section{Pengujian Hipotesis Secara Parsial}

\begin{tabular}{|l|l|l|l|l|l|}
\hline \multirow{2}{*}{ Model } & \multicolumn{2}{|l|}{$\begin{array}{l}\text { Unstandardized } \\
\text { Coefficients }\end{array}$} & $\begin{array}{l}\text { Standardized } \\
\text { Coefficients }\end{array}$ & & \multirow{2}{*}{} \\
\cline { 2 - 4 } & $\mathrm{B}$ & Std. Error & Beta & T & Sig. \\
\hline 1(Constant) & -29.496 & 12.188 & & -2.420 & .018 \\
CP & -1.202 & 1.094 & -.091 & -1.099 & .276 \\
DER & 13.646 & 5.055 & .276 & 2.700 & .009 \\
ROA & 1.690 & .203 & .609 & 8.328 & .000 \\
CR & 24.757 & 3.399 & .666 & 7.284 & .000 \\
AG & 3.793 & 12.553 & -.022 &. .302 & .764 \\
FS & 1.156 & .791 & .120 & 1.461 & .149 \\
\hline
\end{tabular}

Sumber data : Data primer yang diolah

Dari tabel 1 maka didapat persamaan regresi linear berganda sebagai berikut :

$Y=-29.496-1,202 X 1+13,646 X 2+1,690 X 3+24,757 X 4-3,793 X 5+1,156$

$\mathrm{X} 6+\varepsilon \mathrm{P}$ ersamaan regresi dapat dijelaskan sebagai berikut :

Konstanta -29,496 menunjukkan bahwa terdapat Dividend Payout Ratio pada perusahaan manufaktur yang terdaftar pada Bursa Efek Indonesia periode 2011-2013 tanpa adanya variabel lain yang mempengaruhi 
Variabel Cash Position secara parsial berpengaruh negatif dan tidak signifikan terhadap Dividen Payout Ratio pada perusahaan manufaktur yang terdaftar pada bursa efek indonesia periode 2011-

2013, terlihat dari t hitung sebesar - 1,299 > t tabel - 2,109. Dengan demikian hipotesis yang menyatakan bahwa Cash Position berpengaruh terhadap Dividend Payout Ratio ditolak

Variabel Debt Equity Ratio secara parsial mempunyai pengaruh positip dan signifikan terhadap Dividen Payout Ratio terlihat dari t hitung 2,700 > t tabel 2,109 Dengan demikian hipotesis yang menyatakan bahwa Debt Equity Ratio berpengaruh terhadap Dividen Payout Ratio diterima 4. Variabel Return On Asset secara parsial mempunyai pengaruh signifikan terhadap Dividen

Payout Ratio terlihat dari t hitung8,328 $>\mathrm{t}$ tabel 2,109. Dengan demikian yang menyatakan bahwa Return On Asset mempunyai pengaruh terhadap Dividen Payout Ratio diterima.

Variabel Cash Ratio secara parsial mempunyai pengaruh signifikan terhadap Dividend Payout

Ratio terlihat dari t hitung 7,284 >2,109. Dengan demikianHipotesis yang menyatakan bahwa Cash Ratio mempunyai pengaruh terhadap Dividen Pay Out Ratio diterima.

Variabel Asset Growth secara parsial berpengaruh negatif dan tidak signifikan terhadap Dividen Payout Ratio terlihat dari thitung -0,302 > t tabel - 2,109. Dengan demikian Hipotesis yang menyatakan bahwa Asset Growth mempunyai pengaruh terhadap Dividend Payout Ratio ditolak.

K Variabel Firm Size berpengaruh positip tetapi tidak signifikan terhadap DividenPayout Ratio.terlihat dari t hitung 1,461< t tabel 2,109, maka hipotesis yangmenyatakan bahwa Firm Size berpengaruh terhadap Dividen Payout Ratio ditolak. B.

\section{Koefisiensi Determinasi}

Tabel 3

\begin{tabular}{|l|l|l|l|l|}
\hline Model & $R$ & R Square & $\begin{array}{l}\text { Adjusted } \\
\text { R Square }\end{array}$ & $\begin{array}{l}\text { Std. Error } \\
\text { of the } \\
\text { Estimate }\end{array}$ \\
\hline 1 & .839 & .704 & .675 & 15.40085 \\
\hline
\end{tabular}

Sumber data : Data primer yang diolah

Nilai R (koefisien determinasi) adalah sebesar 0,839. Nilai R berada diantara (1) dan 1 , sehingga mempunyai korelasi yang erat. Besarnya nilai square $\mathrm{R}^{2}$ sebesar 0,704 dengan 
JURNAL ECOBISMA VOL 2 NO. 1 JAN 2015

Adjusted R Square adalah sebesar 0,704 yang berarti bahwa pengaruh variabel yang di uji mempunyai pengaruh sebesar 0,675 atau 67,50 \% terhadap variabel Dividen Payout Ratio, sedangkan sisanya dipengaruhi oleh variabel lain yang tidak diteliti dalam penelitian ini.

\section{PEMBAHASAN}

Berdasarkan analisa persamaan regresi berganda didapat hasil pengujian hipotesis bahwa Variabel Cash Position, Debt To Equity Ratio , Return On Asset, Cash Ratio, AssetGrowth, dan Firm Size secara simultan berpengaruh signifikan terhadap Dividend Payout Ratio pada perusahaan manufaktur yang terdaftar pada Bursa Efek Indonesia 7 periode tahun 2011-2013. Hal ini menunjukkan bahwa apabila semakin bagus CashPosition, Debt To Equity Ratio, Return On Asset, Cash Ratio, Asset Growth, dan Firm Size maka Dividend Payout Ratio perusahaan manufaktur yang terdaftar pada Bursa EfekIndonesia periode tahun 2011-2013 akan semakin meningkat.

Hasil uji t menunjukkan Debt Equity Ratio Return On Asset, Cash Ratio secara parsial mempunyai pengaruh positif dan signifikan terhadap Dividend Payout Ratio. Hal ini menunjukkan bahwa apabila semakin bagus Debt To Equity Ratio, Return On Asset, CashRatio, maka Dividend Payout Ratio perusahaan manufaktur yang terdaftar pada BursaEfek Indonesia periode tahun 2011-2013 akan semakin meningkat.

Hasil ini mendukung penelitian yang dilakukan oleh Septiani Arsanda Ari (2011) yang menyatakan bahwa Cash Position tidak berpengaruh terhadap Dividend PayoutRatio. Namun ini berbeda yang ditunjukkan penelitian yang dilakukan oleh Anggit SatriaPribadi (2012) yang menyatakan Variabel Cash Position, Debt To Equity Ratio, ReturnOn Asset, Cash Ratio, Asset Growth, dan Firm Size berpengaruh terhadap Dividend Payout Ratio.

\section{KESIMPULAN DAN SARAN}

Persamaan Regresi Berganda dari hasil penelitian adalah Y $=-29.496-1,202$ X1 + 13,646 X2 $+$

1,690 X3 + 24,757 X4 - 3,793 X5 + 1,156 X6 + $\varepsilon$

Cash Position secara parsial berpengaruh negatif dan tidak signifikan terhadap Dividen Payout Ratio pada perusahaan manufaktur yang terdaftar pada BursaEfek Indonesia periode 20112013.

Debt Equity Ratio secara parsial mempunyai pengaruh positif dan signifikan terhadap Dividen Payout Ratio pada perusahaan manufaktur yang terdaftar pada Bursa Efek Indonesia periode 2011 -2013.

Return On Asset secara parsial mempunyai pengaruh positif dan signifikanterhadap Dividen Payout Ratio pada perusahaan manufaktur yang terdaftar pada Bursa Efek Indonesia periode 20112013.

Cash Ratio secara parsial mempunyai pengaruh positip dan signifikan terhadap Dividend Payout Ratio terlihat dari t hitung 7,284 >2,109. pada perusahaan manufaktur yangterdaftar pada Bursa Efek Indonesia periode 2011-2013. 
Asset Growth secara parsial berpengaruh negatif dan tidak signifikan terhadap Dividen Payout Ratio pada perusahaan manufaktur yang terdaftar pada BursaEfek Indonesia periode 20112013.

Firm Size tberpengaruh terhadap Dividen Payout Ratio. pada perusahaan manufatur yang terdaftar pada Bursa Efek Indonesia periode 2011-2013.

\section{SARAN}

Perusahaan ada baiknya untuk dapat meningkatkan kemampuan dalam manajemen kas, asset, liabilities, dan equity, untuk meningkatkan ratio dari variabel ataupun non

ratio yang mempengaruhi Dividend Payout Ratio, sehingga dapatmeningkatkan Dividend Payout Ratio. 


\section{DAFTAR PUSTAKA}

Riyanto, Bambang, Pembelanjaan Perusahaan, BPFE, 1997

Sartono, Agus, Manajemen Keuangan Teori dan Aplikasi, BPFE, 1994

Sjahrial, Dermawan, Manajemen Keuangan Lanjutan, Mitra Wacana Media, 2007

Arie, Septiani Arsanda. 2011. “ Analisis pengaruh Return on Asset, Debt to equity Ratio,Growth, Frim Size, dan Cash Ratio terhadap DPR pada perusahaan manufakturyang listed di Bursa Efek Indonesia 2005 2008.”. Skripsi Universitas Diponegoro Semarang.

Anggit Satria Pribadi. 2012. "Analisis pengaruh variabel Cash Position, Firm Size,Growth Opportunity, Ownership, dan Return on Asset (ROA) terhadap Dividend Payout Ratio (DPR)". Skripsi Universitas Diponegoro Semarang. 